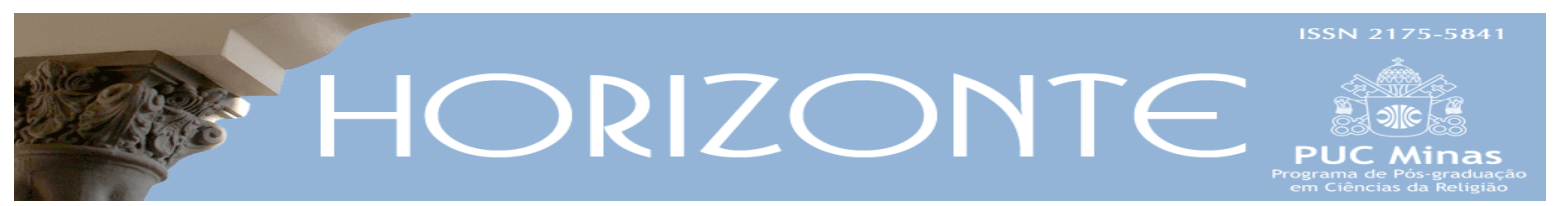

Temática Livre - Artigo Original (c) (1)

\title{
Política religiosa no Brasil
}

\author{
Religious policy in Brazil
}

\author{
Wellington Teodoro da Silva* \\ Francis Albert Cotta*
}

\begin{abstract}
Resumo
Esse artigo apresenta o resultado de estudos sobre as relações entre religião e política no Brasil. Ele trata do tema específico da sacralização da política levada adiante pelo Estado Novo (1937-1945). Esse período político contou com ideólogos que se ocuparam de elaborar legitimações para a política nacional, bem como uma identidade/corpo da nação cujo líder/cabeça era Getúlio Vargas. Por meio do estudo do pensamento de Alcir Lenharo e o suporte de outros autores, espera-se demonstrar que os sentidos de mundo próprios da religião são passíveis de serem importados pela política para conferir-lhe uma dimensão sacralizante com vistas à sua efetividade. A novidade do tema para o caso brasileiro nos fez propor o texto na forma de uma aproximação teórica. Esperamos demonstrar que há um espaço não tratado no tema da secularização na política. Nossa jovem tradição investigativa é marcada mais pela separação das esferas religião e política do que pela distinção. Esperamos contribuir para propor uma nova pauta na agenda desses estudos brasileiros.
\end{abstract}

Palavras chave: Religião e política; Estado Novo; política religiosa.

\begin{abstract}
This essay presents the result of studies about the relationship between religion and politics in Brazil. It deals with the specific topic of sacralization of politics conducted by the "Estado Novo" (1937-1945). That period had ideologists which occupied themselves in legitimating the national politics and an identity/body of nation as well, having Getúlio Vargas as its main leader. Through the research of Alcir Lenharo and the support of other authors this essay intends to show that the perceptions of the world that are typical to religion are passible of being imported by politics to give it a sacralizing dimension having its effectiveness as its goal. The theme for Brazil is new and made us propose the text in the form of a theoretical approach. We hope to demonstrate that there is a space not addressed in the theme of secularization in politics. Our young investigative tradition is marked more by the separation of the spheres 'religion and politics' than the by the distinction. We hope to contribute to propose a new agenda on the agenda of these Brazilian studies.
\end{abstract}

Keywords: Religion and politics; Estado Novo; religious politics.

Artigo recebido em 08 de março de 2016 e aprovado em 06 de junho de 2016.

Agradecemos à FAPEMIG pelo fomento e apoio para a realização desta pesquisa.

* Doutor em Ciência da Religião pela UFJF (2008); pós-doutor em História pela FAFICH/UFMG. É professor do Departamento de Ciências da Religião da PUC Minas. País de Origem: Brasil. E-mail: wteodorosilva@gmail.com

* Doutor com residência pós-doutoral em História (História Social da Cultura), ambos pela UFMG. Atua como Negociador de Crises e Mediador de Conflitos em Minas Gerais. País de Origem: Brasil. E-mail: francis.eod@gmail.com

Horizonte, Belo Horizonte, v. 14, n. 42, p. 627-641, abr./jun. 2016 - ISSN 2175-5841 
“Em primeiro lugar, e, sobretudo, não houve laicização da política, mas apenas um deslocamento do lugar ocupado pela imagem de Deus como poder uno e transcendente: Deus baixou do céu à terra, abandonou conventos e púlpitos e foi alojar-se numa imagem nova, isto é, no Estado".

\section{Introdução}

Marilena Chauí

Este texto tratará de uma dimensão da política brasileira afeita ao modo religioso de estruturar o estar no mundo. Não propomos que a política seja uma prática religiosa no Brasil. Contudo, vez ou outra, ambas se encontram co-fusas, indistintas. Esses momentos permitem acessos hermenêuticos importantes para compreender que a política não é terreno do racional tanto quanto os últimos três séculos esperavam (GIRARDET, 1987). Por seu lado, a religião não é rarefeita em escolhas racionais, ou, dizendo de outra forma, terreno onde grassa a emoção, o simbólico e o imagético de maneira exclusiva.

A aproximação entre esses dois lugares é tema que pede um singular acautelamento. $\mathrm{O}$ caso brasileiro ressente-se de uma tradição acadêmica de maior largueza e profundidade em sua reflexão nessa temática. Preferimos não reputar essa insuficiente lida intelectual às mentalidades e opções teóricas e políticas de nossas ciências humanas quando o tema da política é posto diante da questão religiosa. Propomos que nossa universidade ainda não teve tempo de formular tradições interpretativas. Seguimos ressentindo a ausência de um instrumental conceitual capaz de se apropriar das singularidades brasileiras que, segundo DAMATTA (1993), não se satisfazem com poucos conceitos-chaves, como a Europa e os Estados Unidos. Somos capturados pelo híbrido, pelo composto, pelas improváveis misturas de realidades que se excluem mutuamente. Não somos tanto uma coisa ou outra quanto uma coisa $e$ outra.

Por meio do pensamento de Alcir Lenharo (1986), expresso em sua obra "A sacralização da política”, que se debruça sobre o Estado Novo (1937 - 1945), trataremos de um momento em que a política brasileira buscou modos próprios da religião para que um projeto de nação chegasse à mentalidade da população. Esse 
exemplo de ambivalência religião $\leftrightarrow$ política permite asserções contrárias àquelas que dão conta, de maneira simplificada, de um processo histórico onde a política emancipa-se da religião. A política moderna permanece reivindicando sentidos religiosos, ontologizando-se, servindo-se do universo sagrado para se estabelecer e se auto-reproduzir.

Em seu trabalho, Lenharo (1986) ultrapassa a tessitura da interpretação política em seus próprios termos. Logrou interpretar um ambiente propositor de sentidos de nação mais afeito à maneira pela qual a religião estrutura o estar humano no mundo. Dessa forma, conseguiu demonstrar que os sentidos da imaginação humana de sacralização da realidade podem ser acionados em um projeto de nação.

Em sendo assim, as rotinas intelectuais da análise da religião são adequadas para o estudo da política do período. O fenômeno religioso se torna um dado histórico cuja análise se faz incontornável para a compreensão da sociedade e da história política. Não reatualizamos o dito marxista sobre a crítica religiosa ser a premissa de toda a crítica, bem como não a pensamos como um aroma espiritual e falseador da realidade. Ela é um dado vastamente observado no humano, em todos os tempos da história conhecida e que deve, como tal, ser investigada sem apriorismos e/ou juízos de valor sobre a sua continuada existência. O impressionante conjunto de obras escritas a seu respeito permite-nos tratá-la como lugar de análise necessário para as demais análises do humano incluindo o mundo da política. Sobretudo, quando a política se torna uma realidade autolegitimante que se ontologiza para formar uma comunidade imaginada, como proposto por Benedict Anderson (2008).

\section{O Estado Novo}

Schwarcz e Starling (2015) ratificam a concepção historiográfica de que o “centro de sustentação do Estado Novo estava corporificado funcional e 
pessoalmente na figura de Vargas - único civil a comandar uma ditadura no Brasil, garantida pelas Forças Armadas, em especial pelo exército, e apoiada numa política de massas" (p. 374).

A asserção católica de a Igreja ser corpo místico cuja cabeça é Cristo inspirou a ideia da nação como um corpo político tendo Getúlio Vargas como cabeça. Essa ação deliberada de construção da figura de Vargas pode ser identificada, entre outras ações realizadas pelo Departamento de Imprensa e Propaganda (DIP), na transformação do dia do aniversário de Vargas em festa oficial, com desfiles públicos e programas de rádio. Era uma das facetas do projeto de uma sociedade autoritariamente controlada pelo Estado, com foco no personalismo. Nessa mesma lógica o DIP cunhou a expressão "Pai dos Pobres".

O Estado Novo bebia teoricamente em autores como Alberto Torres, que defendia a tese de que cabia ao Estado organizar a sociedade, fornecer propósito à nação e implantar as nuanças necessárias. Essa ênfase no poder Executivo, corporificado em Getúlio Vargas, era tributária da ditadura do Estado Novo português, criada em 1932, por Salazar. O Estado Novo Brasileiro, a despeito de não ser caracterizado como fascista, compartilhava outros traços do fascismo europeu, tais como a supressão do dissenso e a "representação de interesses de grupos e classes sociais num arranjo corporativo, isto é, sob a forma de uma política de colaboração entre patrões e empregados, tuteladas pelo Estado" (SCHWARCZ; STARLING, 2015, p. 375). Assim, Vargas além de ser o "pai dos pobres" seria a "mãe dos ricos".

A teoria corporativa do poder e da sociedade do Estado Novo possui matriz lusitana de longa duração. Na perspectiva medieval portuguesa, a teoria corporativa do poder e da sociedade via o conflito como uma enfermidade a ser tratada para a conservação da saúde do corpo social. Era baseada na ideia de harmonia do Corpo Social. Essa concepção trouxe consigo metáforas que impregnaram uma visão maniqueísta da realidade social que a influenciou. 
Na segunda metade do século XVIII teria coexistido, em terras portuguesas, duas dimensões do entendimento da sociedade e do poder: a corporativa e a voluntarista. Na dimensão corporativista o poder político é concedido diretamente por Deus ao Rei e não mais pela comunidade. Tal deslocamento implicou, e justificou a concentração institucional e efetiva do poder político na Coroa, isto é, ao poder central coube a execução das tarefas concernentes ao ordenamento social em função do bem comum.

O corpo como símbolo é recorrente no trânsito entre os ambientes religiosos e políticos. Ele possui porosidades e hibridismos capazes de produzir sínteses de sentidos e significados comuns, ao ponto de deixar a religião e a política numa zona de indistinção. Essa sua capacidade de ser lugar de co-fusão identitária é multissecular e central tanto nos ambientes religiosos quanto nos políticos do ocidente.

Sobre esse tema vale citar o trabalho seminal The King's two bodies: a study in medieval political theology, publicado em 1957 pela Princeton University Press. Nele, Ernst Kantorowitcz estuda a doutrina de que o rei possui um corpo político e um corpo místico, formulada pelos juristas da Inglaterra do século XVI. Eles produziram um pródigo pensamento jurídico-teológico, onde os campos da política e da religião eram indistintos. Imanência e transcendência se co-fundiam na pessoa do Rei.

O governo pós-30 adotou uma política social protecionista em troca de uma domesticação política, com o objetivo precípuo de solucionar a crise de participação contextualizada num ambiente de baixa institucionalização política.

Entre 1930 e 1945, prevaleceu o padrão de incorporação política que possuía como fonte de inspiração o modelo corporativista, em que o Estado tutelava as massas urbanas. A posição na estrutura trabalhista condicionava a identidade política e, por conseguinte, aqueles que estavam fora da estrutura sindical não pertenciam à comunidade política. Nesse contexto, desenvolveu-se uma visão 
corporativa da sociedade, ao invés da necessária tradição pluralista, o que afetou de maneira profunda a cultura política brasileira (REIS; CHEIBUB, 1997).

O período do Estado Novo representou a passagem definitiva de uma sociedade de base agrária para uma sociedade urbano-industrial. O caráter autoritário do Estado reprimiu a ascensão dos movimentos tanto de esquerda como de direita, além de diminuir a autonomia das Unidades Federativas Estaduais, ao concentrar no governo federal quase todo poder decisório e administrativo referente às políticas sociais.

\section{Projeto de nação do Estado Novo: política religiosa}

Os teóricos estado-novistas organizaram os sentidos políticos da nação recusando o período terminado em 1930. Esse corpo de ideólogos não constituía "uma doutrina oficial compacta" de modos a recusar a coexistência de distinções de pensamento. Contudo, pode-se encontrar um núcleo compreensivo, um temário central, “capaz de caracterizar um determinado projeto político” (GOMES, 2010. p. 189).

O novo momento político conduziu o processo de re-elaboração da nação pelo corpo de intelectuais do regime. Os sentidos do novo inaugurado por uma revolução; a proposta de fazer emergir o povo brasileiro, categoria sempre vaga; bem como a centralização do poder conduziu para uma espiritualização do regime. Esses ideários esperavam se inserir no nível das mentalidades, cujo acesso não ocorre por meio de argumentos racionais.

Para esse fim, elaborou-se sofisticadas liturgias políticas que, com sua efetualidade (AGAMBEM, 2013), formavam mentalidades e sentidos de nação. Houve largo aproveitamento daquilo que havia disponível na cultura e no cotidiano do homem e da mulher comuns, marcados pela religião como estruturadora do estar no mundo. Esse empenho fez a política de formação da nação avizinhar-se de 
discursos e sentimentos próprios da religião. Nesse sentido, esse nível de associação entre esferas parece recusar certo sentido de modernidade, objeto de um corpo hegemônico de análises sobre a secularização que, recorrentemente, empenham-se em separar ao invés de distinguir.

Alcir Lenharo (1986) conduz um corpo de interpretação filiado à compreensão durkheimiana. Assevera que ao mover-se pela solidariedade orgânica a sociedade torna-se “portadora de uma excelência própria da vida religiosa” (1986. p. 154) e cita Durkheim: “Se a religião engendrou tudo que há de essencial na sociedade, é que a ideia de sociedade é a alma da religião. ‘... o fiel não se engana quando crê na existência de um poder moral do qual depende ao qual deve o melhor de si mesmo; este poder existe; é a sociedade... Deus não é mais do que a expressão figurada da sociedade" (LENHARO, 1986. p. 145).

A seguir, faz alusão ao marxismo como "aplicação sui generis das bemaventuranças Evangélicas”, ao colocar para o operário (pobre e humilde) "a obra da sua própria redenção” (LENHARO, 1986. p. 147). Recorre, ainda, a Francisco Campos em suas preocupações pelo aspecto trágico do seu momento presente, que considera uma época de transição. O mundo estaria passando por profundas mudanças e ainda não haviam aparecido as novas "formas espirituais" que pudessem substituir as antigas já obsoletas. Segundo Campos, nunca um número tão grande de "pontos de fé" foi posto em questão (LENHARO, 1986. p. 151). Os grifos dessas expressões foram feitas por Lenharo a relevância da dimensão não racional como organizadora das realidades política e social.

Numa compreensão que se avizinha do ambiente teórico e de fé positivistas, ele assegura que as massas predispõem-se intelectualmente ao mergulho no irracional; elas não operam segundo a discursividade formal da razão, mas por meio de "imagens e mitos, intérpretes dos seus desejos libertadores das forças elementares da alma humana” (LENHARO, 1986. p. 153). No campo da política, o pensamento mítico do salvador continua sendo reatualizado. A história continua 
sendo uma história da salvação, ainda que no imanente. O comunismo e o nazismo tinham em comum a operosidade desse pensamento mítico.

A propaganda do Estado Novo empenha-se em mostrá-lo como um corpo sacralizado, uma realidade ontologizada e não como mero arranjo político ao lado de outros arranjos possíveis. Ele é apresentado como um ser de virtudes num combate demiúrgico contra o socialismo e o liberalismo, que terçam as mesmas armas para serem significados numa guerra de símbolos, imagens e ritos (RIVIÉRE, 1989). Fez largo uso de símbolos, mitos, imagens e ritos como mediadores e/ou produtores de sentidos, vontade política e formulação da compreensão de si da nação. Com esse fim, ele promoveu diversos eventos litúrgicos - marchas, procissões, eventos esportivos e musicais - como meios de se apresentar

como o único sujeito histórico adequado ao país para aquele momento e, ao mesmo tempo, o corretor de sua linha de evolução histórica. Daí a utilização do fato mítico da Revolução de 1930, da qual 37 se apresentará como revolução acabada e da qual tomará de empréstimo sua origem mítica de fundação. (LENHARO, 1986. p. 13 e 14)

Essas mediações e efetualidades litúrgicas no campo da política causam estranhamento em Ernst Cassirrer (2003). Segundo ele, em uma época onde a razão é responsável por tantos progressos para o humano, ela permanece rarefeita na política. Nela, os sentimentos produzem mais adesões do que a racionalização. O sentimento mostra-se capaz de mobilizar as vontades de maneira insuperável. Por meio dele, a vontade transcende a pessoa, o grupo e a nação. É capaz de propor ideias que são assumidas por cada um como se fosse sua. Os símbolos e ritos permitem que a pessoa sinta-se co-elaboradora da vontade de todos e da sua própria. Em sendo assim, acompanhamos a assertiva de Francisco Campos: “'A integração política' pelas forças irracionais é uma integração total, porque o absoluto é uma categoria arcaica do espírito humano. A política transforma-se dessa forma em teologia” (CAMPOS apud LENHARO, p. 153). 
Ao mesmo tempo que ente sagrado, a nação também é pensamento, energia, ação, matéria. Estão dadas, portanto, as duas naturezas distintas desse corpo único, religioso e social. Sua dimensão material é focalizada pelos humildes elementos humanos desse conjunto, que veem sua contribuição. Não somente se transformar em necessária para o todo, como necessária uns para os outros. Finalmente, de volta à primeira condição, a nação alça-se a uma posição divina, que tudo vê do alto, por mais insignificante que seja o detalhe, que tudo compreende, que tudo assimila. Enquanto totalidade, a nação parece assemelhar-se à crença cristã da total visibilidade a que o fiel se submete aos olhos de Deus: “'Deus me vê"' (LENHARO, 1986, p.191-192).

Lenharo (1986) defende a tese de que a necessária "comunhão totêmica" produz "novas categorias de pensamento e ação e de processos espirituais" com a conseguinte integração política. Lança mão do exemplo do totalitarismo alemão que se elabora como uma nova religião com caráter secular "a ponto de espantar e causar repulsa ao Vaticano".

Desde o programa de 1929 do NSDAP, os nazistas dão início à pregação do Cristianismo Positivo; nas palavras do ministro dos negócios da Igreja, de 1937, não mais o cristianismo da fé em Cristo, Filho de Deus e sim o cristianismo convocado pelo partido e pelo Fürer, o precursor de uma nova "revelação", o "novo redentor", na apreciação de Roehm. Na escalada de repressão às igrejas cristãs, o momento talvez mais intenso por ser apanhado do programa de 30 pontos, para a criação da Igreja Nacional do Reich. Esse documento fora redigido por Rosenberg e apresentado durante a guerra: nele pregava abertamente a nacionalização das igrejas, o extermínio das crenças cristãs, o fim dos padres e pastores, a cessação de publicação da Bíblia, substituída pelo novo livro sagrado, Minha Luta, a retirada dos crucifixos, bíblias e imagens das igrejas e a substituição da cruz cristão pela suástica. (LENHARO, 1986, p. 153-154).

A construção do poder político acontece num processo sacralizador da política que elabora sua própria teologia (SCHIMMIT, 1992).

Em 1937, Carl Schimitt, um defensor da vontade hitleriana, escreveu o texto clássico do pensamento totalitário. Trata-se do pouco citado Totaler Feind, Tolaler Krieg, Totaler Staat. Nele são definidos os sofismas do pensamento oposto à convivência, ao debate, à democracia. Não basta que o adversário seja perseguido. Ele precisa ser posto numa outra dimensão metafísica. O Brasil não entrou com muito atraso na cruzada em prol dessa ideologia. Já em 1936, Tristão de Athayde, partindo das mesmas fontes doutrinárias de Carl Schimitt, sobretudo de Bonald mais os autores da contra revolução semântica, afirma em alto e bom tom que "nosso inimigo" estava, enquanto doença, diagnosticado. Tratava-se do comunismo (DUTRA, 1997, p. 9). 
Esse cosmo sagrado produzia o sentido de transcendência da nação. Após breve asserção sobre o mistério da fé no multissecular ritual da transubstanciação, acudido pela análise jungiana, Lenharo analisa a apresentação do corpo e do sangue no terreno político a partir de fragmento de discurso de Getúlio Vargas:

Devo dizer-vos que o Brasil, politicamente, é uma unidade. Todos falam a mesma língua, todos têm a mesma tradição histórica e todos seriam capazes de se sacrificar pela defesa de seu território. Considerando-a uma unidade indivisível, nenhum brasileiro admitiria a hipótese de ser cedido um palma dessa terra, que é o sangue e a carne do seu corpo. (Discurso de Goiânia, agosto de 1940, A nova política do Brasil, volume VIII, 1941, p. 24). [grifos feitos por Lenharo] (LENHARO, 1986 p. $110){ }^{1}$

As expressões grifadas indicam "os contrabandos do discurso católico para a liturgia política” (LENHARO, 1986, p. 110). Influenciada por certa teologia sacrificial, o discurso apresentou a disposição para o martírio. Corpo e sangue já eram linguagens simbólicas presente no imaginário popular e Getúlio Vargas as utilizou como transubstanciadoras da união política da nação. Jesus Cristo é inserido como exemplo no terreno da política nacional por duas vezes: a primeira quando é politicamente sincretizado em Tiradentes, o Cristo Cívico, e a segunda em seu corpo e sangue. Se ele se sacrificou pelos fieis, os cidadãos deveriam se sacrificar pela nação. O contato de Vargas com o Cardeal Dom Sebastião Leme fê-lo compreender a importância de manejar a mentalidade cristã da nação (SANTO ROSÁRIO, 1962). Na propaganda do Estado Novo Getúlio Vargas chegou a ser comparado com Jesus Cristo "porque se sacrificava pelo povo" (CAPELATO. 2003, p. 124).

Vê-se, desse modo, como o imaginário do 'plasma' nacional beneficia-se diretamente do conteúdo religioso popularmente disseminado entre as populações de origem cristã e particularmente católica do país (LENHARO, 1986, p. 111).

\footnotetext{
${ }^{1}$ Lenharo também traz exemplos de discurso de Getúlio Vargas feitos no Pará e em Santa Catarina para colonos alemães, nos quais utiliza os mesmos símbolos religiosos do cristianismo para produzir sentido político para a nação.
} 
A construção da ideia de "Pátria" a partir de valores nativos do terreno da religião compõe o núcleo da estratégia política do período. Em janeiro de 1936 Vargas, logo após estabelecer o Estado de Sítio e modificar a Lei de Segurança Nacional para facilitar a repressão, assim asseverou:

\begin{abstract}
No limiar do novo ano, quando entre festividades e efusões de alegria, rodeadas pelas criaturas que amais e pelas pessoas que vos dão conforto de uma estima leal e dedicada, expandis os vossos afetos e sentimentos, deveis ter também um pensamento votivo para a nossa Pátria, que seja penhor inflexível decisão na sua defesa (...) deveis levantar a vossa alma, pelo amor do Brasil, numa afirmação de fé, num impulso glorioso, bem compreendendo o momento, colaborando com os poderes públicos, resistindo à pressão destruidora da violência, de fraude e de dissimulação do comunismo, realizando, enfim, a união sagrada de todos pelo ideal supremo de honrar o nosso passado e de acrescer as glórias dos que nos precederam na obra imortal de construção de uma Pátria cada vez maior, mais próspera e mais feliz² (Grifos nosso).
\end{abstract}

No discurso de Vargas, a ideia de nação é revestida de uma devoção amorosa, onde a estrutura da nacionalidade está sustentada no tripé família, religião e pátria. Estrutura também recorrente no lema integralista "Deus-Pátriae-Família”. Nessa lógica, temos que a mãe é o suporte da família, a família é a essência da pátria, a Família é o suporte do Estado e da Nação, portanto, todos os brasileiros são seus filhos e irmãos. Dessa forma, as relações do povo brasileiro entre si e do povo brasileiro com a Nação, em vez de relações de cidadania, são relações de filiação. A Nação é informada pelos valores de respeito e obediência à autoridade e pelo valor de preservação da harmonia e da coesão (DUTRA, 1997, p.164).

Sobre o Estado burguês, Lenharo se aproxima da compreensão de Robert Bellah (2006) que considera que esse arranjo político não baniu a religião cristã (BELLAH, 2006). Considera mais adequado propor que os sinais cristãos foram afastados da visualidade imediata. Esses sinais e sentidos continuam a existir e com eles "os conteúdos cristãos de uma dimensão sacralizada de poder, mas operando nos poros do corpo político do Estado” (p. 155).

\footnotetext{
2 Boletim do Ministério do Trabalho, Indústria e Comércio. N. 17, jan. 1936 apud DUTRA, 1997, p. 154.
} 
Assim como fizeram Ernst Kantorowicz (1998), Carl Schmitt (1992) e Claude Rivère (1989), Lenharo demonstra como a doutrina formulada pela teologia católica foi adaptada para o que-fazer político dos Estados nacionais. De ser assim, o processo de secularização não conduziu à ausência da religião; “os valores espirituais cristãos têm-se mantido atuantes, como tem, aliás, acontecido no seio da sociedade." (LENHARO, 1986. P. 155)

Operando em uma matriz cultural monoteísta, a política esvaziou os temas, verdades e imagens cristãs de seus conteúdos originais. Todavia, manteve suas formas que seguiam orientando os sentidos do próprio Estado, inclusive sua rotina sacralizadora. Para além da dimensão simbólica e litúrgica, Carl Schmitt (1992) afirma que as categorias fundamentais do Estado são conceitos teológicos secularizados. Eles também passaram pelo processo de perda do sentido e conteúdo originais, mantendo-se a estrutura. Dessa forma, o Estado moderno se despoja da visibilidade imediata e do conteúdo original dos símbolos e teologias cristãs, imanentizado-os em seus próprios símbolos litúrgicos e teologias políticas (LENHARO, 1986; RIVIÈRE, 1989).

Vale assentir para a plausibilidade da afirmação de que o monoteísmo cumpriu papel do pedagogo, que preparou as mentalidades para a organização desse Estado e a sua invasão nas esferas próprias da tradição católica (DURKHEIM, 1989; BLOCH, KANTOROVICH, 1998; RIVIÈRE, 1989).

Nessa compreensão, Lenharo (1986) considera que o processo de sacralização do poder estatal, necessário para a construção da legitimidade de seu impressionante monopólio, copiou a organização da Igreja Católica, sua estrutura hierárquica, disciplinar e sistema educacional próprio. O poder salvador de condução dos povos sempre exerceu fascínio quase místico. No caso do Estado, esse poder fez de seus funcionários e burocratas os novos doutores da lei. Sendo assim, Lenharo afirma que a Igreja prestou mais serviços ao Estado do que recebeu compensações na década de 1930. Ela deu “apoio político decisivo em momentos 
cruciais da década” e agiu na domesticação das consciências. (LENHARO, 1986, p. 190). Portanto, ele segue na constatação de Cassiano Ricardo sobre os "elementos de natureza irracional que condicionam a formação das bases do Poder" (LENHARO, 1986, p. 67).

No terreno propriamente católico, as encíclicas Rerum Novarum e Quadragésimo Anno fundamentaram a preocupação estado-novista com a dignidade do trabalhador. A intelectualidade católica elaborou uma útil espiritualidade do trabalho para os subalternos, enquanto que as elites técnicas cuidariam dos seus aspetos técnicos racionais. Pandiá Calógeras (1932) escreveu que Jesus

quis nascer operário, entre operários. Entre eles escolheu seus apóstolos, e estes continuaram a tradição, trabalhando em meio a fadigas de sua árdua missão. Pregaram sempre, pela palavra, e pelo exemplo, a obrigatoriedade do labor, assim também a Igreja, que a seus filhos impões sempre a lei do trabalho (CALÓGERAS, P. Conceito christão do trabalho. São Paulo: Cia Ed. Nacional, 1932, p. 44 Apud LENHARO, 1986, p. 89).

O uso de símbolos e a secularização da teologia católica pôde ser sentido como ameaça pela Igreja Católica. Contudo, em sua estratégia de cristandade, essa co-fusão pareceu-lhe meio pelo qual poderia influir no ambiente do poder estatal. Em sua estratégia, os riscos de secularização de sua teologia era um dado menor diante da possibilidade de sua cultura penetrar a ideia que o Estado e a nação faziam de si. Apenas após o governo de Juscelino Kubtschek ela descobriu, na fala de Dom Hélder Câmara, os riscos da proximidade com o Estado.

\section{Considerações finais}

Os estudos das relações entre religião e política podem conduzir a descobertas que pedem que a secularização seja um exercício de distinguir ao invés de apenas separar as duas esferas. São recorrentes os exemplos em que a política 
fez uso dos meios de produção de sentidos próprios da religião para se legitimar a si própria e a construção de seus edifícios jurídicos.

O caso brasileiro demonstra que os modos de interpretar o mundo segundo matrizes de sentido e significado próprias da religião avançaram no período republicano encontrando um momento exemplar no Estado Novo. Experiências autoritárias da Europa também demonstram que a política não se emancipou da religião de maneira completa. Ela a tem como uma pedagoga.

O próprio Estado Nacional Moderno empenha-se em fazer-se compreendido longe de um sentido meramente político. Se assim o fosse, ele seria um mero arranjo de poder ao lado de tantos outros possíveis. Ficaria assim numa constante crise de legitimidade, mesmo as democracias. Sua forma de legitimar-se o promove como coisa ontologizada, em si suficiente e legitimada. A ideia de ontem eterno, dos pais fundadores, do poder que emana do povo são algumas formas pelas quais o Estado se ontologiza.

O caso brasileiro segue fértil para análise para estudos como o do Estado Novo onde a política não se compreende como refém da religião. Ao contrário, por meios de mitos, símbolos e liturgias ela lança mão dos meios elaborados anteriormente pela religião para seus próprios fins de construir uma nação. Assim como Lenharo, pensamos ser plausível acompanhar Durkheim (1989) em sua asserção de que a religião fundou as matrizes de nossa cognição. Ainda não houve tempo histórico para refundá-las. Se é que essa refundação é um problema para real que se apresenta para a humanidade.

\section{REFERÊNCIAS}

AGAMBEN, Giorgio. Opus dei. São Paulo: Boi tempo, 2013.

ANDERSON, Benedict. Comunidades Imaginadas - reflexões sobre a origem e a difusão do nacionalismo. São Paulo: Cia das Letras, 2008. 
BELLAH, Robert. Readers. Durham: Duke University Press, 2006.

CAPELATO, Maria Helena Rolim. Multidões em cena - propagando política no varguismo e no peronismo. Campinas: Papirus, FAPESP, 1998.

CASSIRER, Ernst. O mito do Estado. São Paulo: Códex, 2003.

CHAUÍ, Marilena. Cultura e democracia: o discurso competente e outras falas. São Paulo: Cortez, 2011.

DAMATTA, Roberto. Sete ensaios de antropologia brasileira. Rio de Janeiro: Rocco, 1993.

DURKHEIM, Émile. As formas elementares da vida religiosa. São Paulo: Edições Paulinas, 1989.

DUTRA, Eliana. O Ardil Totalitário: imaginário político no Brasil dos anos 30. Rio de Janeiro: Editora UFRJ, Belo Horizonte: Editora UFMG, 1997.

GIRARDET, Raoul. Mitos e mitologias políticas. São Paulo: Cia das Letras, 1987.

GOMES, Ângela Maria de Castro. A invenção do trabalhismo. 4. ed. Rio de Janeiro: Editora FGV, 2010.

KANTOROVICH, Ernst. Os dois corpos do rei: um estudo sobre teologia política medieval. São Paulo: Cia das Letras, 1998.

LENHARO, Alcir. Sacralização da política. Campinas: Papirus, 1986.

MOLINA, Ana Heloísa. Fenômeno Getúlio Vargas: Estado, discursos e propagandas. Hist. Ensino. Londrina, V. 3. Pp. 395 - 112, 1997.

REIS, Elisa P. e CHEIBUB, Zairo B. Pobreza, Desigualdade e Consolidação

Democrática. Revista do Serviço Público. Ano 48, número 3. 1997. pp-135-152.

RIVIÈRE, Claude. As liturgias políticas. Rio de Janeiro, 1989.

SANTO ROSÁRIO, Irmã Maria Regina. (Laurita Pessoa Raja Gabaglia). O cardeal Leme (1882 - 1942). Rio de Janeiro: Livraria José Olympio Editora, 1962.

SCHWARTCZ, Lilian Moritz; STARLING, Heloisa Murgel. Brasil: uma biografia. São Paulo: Companhia das Letras, 2015.

SCHMITT, Carl. O conceito do político. Petrópolis: Vozes, 1992.

SOUZA, Miguel Nicácio Oliveira. O discurso político do Estado Novo. Dissertação de mestrado em Ciência Política. Faculdade de Filosofia, Letras e Ciências Humanas. Universidade de São Paulo. 2008. 